\title{
Article
}

\section{Sex differences in ACL loading and strain during typical athletic movements: a musculoskeletal simulation analysis}

Sinclair, Jonathan Kenneth, Brooks, Darrell and Stainton, Philip

Available at http://clok.uclan.ac.uk/25589/

Sinclair, Jonathan Kenneth ORCID: 0000-0002-2231-3732, Brooks, Darrell

ORCID: 0000-0002-4094-5266 and Stainton, Philip (2019) Sex differences in ACL loading and strain during typical athletic movements: a musculoskeletal simulation analysis. European Journal of Applied Physiology, 119 (3). pp. 713721. ISSN 1439-6319

It is advisable to refer to the publisher's version if you intend to cite from the work. http://dx.doi.org/10.1007/s00421-018-04062-w

For more information about UCLan's research in this area go to http://www.uclan.ac.uk/researchgroups/ and search for <name of research Group>.

For information about Research generally at UCLan please go to http://www.uclan.ac.uk/research/

All outputs in CLoK are protected by Intellectual Property Rights law, including Copyright law. Copyright, IPR and Moral Rights for the works on this site are retained by the individual authors and/or other copyright owners. Terms and conditions for use of this material are defined in the policies page.

\section{CLoK}

Central Lancashire online Knowledge www.clok.uclan.ac.uk

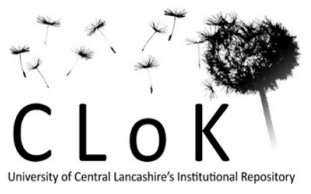




\section{musculoskeletal simulation analysis.}

\section{Abstract}

4 Purpose: Female athletes experience anterior cruciate ligament (ACL) injuries at a much 5 greater rate than males, yet the mechanisms responsible for this are not well understood. The 6 current investigation aimed using a musculoskeletal simulation based approach, to examine $7 \quad$ sex differences in ACL loading parameters during cut and hop movements.

8 Methods: Fifteen male and fifteen female participants completed $45^{\circ}$ cut and maximal one 9 legged hop movements. Three-dimensional motion capture and ground reaction force data during the stance phase of the cut movement and landing phase of the one legged hop were

11 obtained. Lower extremity muscle forces, ACL forces and ACL strains were extracted via a 12 simulation based approach using a musculoskeletal model, with an ACL insertion into the 13 femur and tibia.

14 Results: During the hop movement females were associated with significantly greater peak 15 ACL forces $($ male $=15.01 \mathrm{~N} / \mathrm{kg} \&$ female $=15.70 \mathrm{~N} / \mathrm{kg})$ and strains $($ male $=6.87 \% \&$ 16 female $=10.74 \%)$. In addition, for both the cut $($ male $=4.45 \&$ female $=1.45)$ and hop $($ male $17=2.04 \&$ female $=1.46)$ movements the soleus/ gastrocnemius ratio was significantly larger 18 in males.

19 Conclusions: The current investigation provides new information regarding sex differences 20 during athletic movements that provide further insight regarding the increased incidence of 21 ACL injuries in females. 
24 Although engagement in regular physical activity and sport is associated with a variety of physiological and psychological benefits (Warburton et al., 2006), participation in athletic activity is allied to a high risk from musculoskeletal injury (Finch et al., 2001). The knee is the most commonly injured musculoskeletal site (John et al., 2016), and the anterior cruciate ligament (ACL) is the most frequently disrupted knee ligament (Evans et al., 2014). The ACL is essential for the provision and maintenance of knee stability during dynamic activities (Ellison et al., 1985). With its functional properties and complex anatomy, the ACL is acutely competent in limiting both excessive anterior tibial translation and coronal/ transverse plane knee movements (Dargel et al., 2007).

ACL injuries are predominantly, non-contact in nature, in that the structural integrity of the ligament becomes compromised without physical contact between athletes (Boden et al., 2010). Mechanically, ACL injuries occur when the ligament experiences excessive tensile forces and strains (Smith et al., 2012). Aetiological analyses have shown that the ACL is most vulnerable in the period following foot contact with the ground, in tasks involving sudden decelerations, landings and cutting manoeuvres (Olsen et al., 2004). Athletes with ACL rupture typically undergo reconstructive intervention using auto/ allografts to stabilize the knee (Gottlob et al., 1999; Kaeding et al., 2015). Although the accelerated rehabilitation program developed by Shelbourne et al., (1992) has significantly shortened recovery time following surgery, ACL reconstruction is still preceded by a significant and aggressive period of rehabilitation, with total allocated costs exceeding \$3.4 billion (Gottlob et al., 1999). Importantly, the ACL is associated with poor healing capacity and the risk of a second injury is as high as $30 \%$ in the ipsilateral knee (Di Stasi et al., 2013). ACL injuries frequently lead to chronic knee pain, and athletes who experience an ACL pathology are as many as 10 times more susceptible to early-onset degenerative knee osteoarthritis in (Øiestad et al., 2009), 
49 leading not only to a decline in athletic participation but also enduring disability in later life quality of life, and degenerative joint disease secondary to ACL injury imposes a significant economic burden (Mather et al., 2013).

Importantly, epidemiologic analyses have shown that female athletes have a 2-8 fold increased risk of ACL pathology in relation to age-matched males of similar athletic ability (Arendt et al., 1999). Increased ACL injury risk allied to enhanced participation in athletic activities in females has fuelled a range of comparative and interventional biomechanical investigations aimed at identifying modifiable risk factors. However, the precise aetiology of ACL injury is currently disputed within clinical/ biomechanical literature, with some advocating a predominantly sagittal plane ACL injury mechanism (Yu \& Garrett, 2007), and others supporting the notion that lower extremity coronal and transverse plane loads and movements are also associated with ACL injury risk (Wascher et al., 1993; Markolf et al., 1995; Krosshaug et al., 2007; Boden et al., 2009). Females have been proposed to exhibit riskier landing mechanics during dynamic activities that are linked with ACL injury (Voskanian, 2013). Indeed, three-dimensional kinetic and kinematic analyses have shown that females exhibit reduced hip, knee and ankle flexion angles, enhanced knee valgus angles, larger ground reaction forces (GRF), greater tibia anterior shear forces, larger knee extension and valgus moments, greater hip internal rotation, hip adduction and knee rotation during deceleration or landing manoeuvres (Decker et al., 2003; Malinzak et al., 2001; Chappell et al., 2002; Lephart et al., 2002; Ford et al., 2003; Lin et al., 2012; Sinclair et al., 2012). 
72 During single limb landing and deceleration activities, anterior tibial translation is primarily restrained by the ACL, therefore the knee joint must be stabilized and protected from excessive loads on the joint's soft tissue and ligaments (Quatman \& Hewett, 2009). Muscle recruitment patterns play a key role, and appropriate muscular preference, recruitment and timing, are essential for the maintenance of knee joint stability (Li et al., 1999). As they span the knee joint, the hamstring and quadriceps muscle groups are considered crucial in moderating ACL loading (Shimokochi \& Shultz, 2008). Indeed, numerous analyses have revealed that the quadriceps serve to produce anterior tibial translation and thus increase ACL loading, whereas the hamstring muscle group are act to oppose tibial translation and thus attenuate ACL loads (Baratta et al., 1988; Solomonow et al., 1987; Draganich \& Vahey, 1990; Durselen et al., 1995; Li et al., 1999; Markolf et al., 2004). Importantly, previous analyses have shown that females exhibit quadriceps dominance during landing, and take longer to generate maximum hamstring torque than their male counterparts (Hewett et al., 1996; Huston et al., 1996). Several electromyographical analyses have confirmed this notion using the hamstring/ quadriceps ratio. Females are habitually associated with lower values than males, indicating greater relative involvement of the quadriceps in relation to the hamstrings (Ebben et al., 2010; Landry et al., 2007; Nagano et al., 2007). This is also considered a key mechanism that predisposes female athletes to ACL injury (Ruan et al., 2017). In addition, recent analyses have also shown that muscles may not need to cross the knee joint in order to contribute to ACL loading. Indeed, both Mokhtarzadeh et al., (2013) and Adouni et al., (2016) have demonstrated the agonistic function of the soleus muscle in ACL loading. However, there has yet to be any investigation to examine sex differences in soleus muscle function during typical athletic movements. 
96 Numerous prevention programmes have been devised in order to address mechanisms linked

97 to the aetiology of injury, which have had some success in attenuating the rate of ACL injuries (Caraffa et al., 1996; Hewett et al., 1999; Myklebust et al., 2003; Mandelbaum et al., 2005; LaBella et al., 2011). However, the efficacy of any intervention is dependent on a sound comprehension of the underlying causative mechanisms of the associated condition, and the aetiology for this gender discrepancy is not completely understood (Dai et al., 2014). To date there has yet to be any investigation, which has examined sex differences in ACL loading and strain parameters during athletic movements, principally due to the inability to non-invasively quantify ACL loads and strain during high-risk athletic movements (Kar \& Quesada, 2012). Furthermore, there has also yet to be any investigation which has concurrently examined sex differences in GRF's, three-dimensional knee kinematics and muscle forces during athletic movements. However, advances in musculoskeletal simulation software and enhancements in algorithmic complexity have led to the development of a bespoke model with a six degrees of freedom at the knee joint and the inclusion of a passive ACL inserted into the femur and tibial segments (Kar \& Quesada, 2012). To date however, this more advanced model has not yet been utilized to explore sex differences in ACL loading and strain during high-risk athletic movements.

The aim of the current investigation was to examine sex differences in ACL loading, GRF's, three-dimensional knee kinematics and muscle forces during cut and hop movements using a musculoskeletal simulation based approach. In light of the increased incidence of ACL pathologies in female athletes, the high likelihood of re-injury and the chronic reductions in both musculoskeletal health and athletic functionality, it can be concluded that further insight into the biomechanical differences between males and female athletes would be of both 
practical and clinical significance. The current investigation tests the hypothesis that females will be associated with greater ACL loading parameters during both cut and hop movements.

\section{Methods}

\section{Participants}

Fifteen male (age $30.1 \pm 5.2$ years, height $1.75 \pm 0.1 \mathrm{~m}$ and body mass $77.1 \pm 10.8 \mathrm{~kg}$ ) and fifteen female (age $29.6 \pm 5.6$ years, height $1.66 \pm 0.1 \mathrm{~m}$ and body mass $65.8 \pm 9.9 \mathrm{~kg}$ ) recreational athletes volunteered to take part in the current investigation. All participants were free from lower extremity musculoskeletal pathology at the time of data collection and had not undergone surgical intervention of the knee joint. All provided written informed consent and ethical approval was obtained from the University of Central Lancashire, in accordance with the principles documented in the declaration of Helsinki.

\section{Procedure}

Participants completed five repeats of two sport specific movements; one legged hop and $45^{\circ}$ cut. To control for any order effects the order in which participants performed in each movement condition were counterbalanced. Kinematic information was obtained using an eight camera motion capture system (Qualisys Medical AB, Goteburg, Sweden) using a capture frequency of $250 \mathrm{~Hz}$. To measure kinetic information an embedded piezoelectric force platform (Kistler National Instruments, Model 9281CA) operating at $1000 \mathrm{~Hz}$ was utilized. The kinetic and kinematic information were synchronously obtained and interfaced using Qualisys track manager. 
143 To define the anatomical frames of the thorax, pelvis, thighs, shanks and feet retroreflective 144 markers were placed at the C7, T12 and xiphoid process landmarks and also positioned 145 bilaterally onto the acromion process, iliac crest, anterior superior iliac spine (ASIS), 146 posterior super iliac spine (PSIS), medial and lateral malleoli, medial and lateral femoral 147 epicondyles, greater trochanter, calcaneus, first metatarsal and fifth metatarsal. Carbon-fibre tracking clusters comprising of four non-linear retroreflective markers were positioned onto the thigh and shank segments. In addition to these the foot segments were tracked via the calcaneus, first metatarsal and fifth metatarsal, the pelvic segment was tracked using the PSIS and ASIS markers and the thorax segment was tracked using the T12, C7 and xiphoid markers. Static calibration trials were obtained with the participant in the anatomical position in order for the positions of the anatomical markers to be referenced in relation to the tracking clusters/markers, following which those not required for dynamic data were removed.

Data were collected during the cut and hop movements according to below procedures:

Cut

Participants completed $45^{\circ}$ sideways cut movements using an approach velocity of $4.0 \mathrm{~m} . \mathrm{s}^{-1}$ $\pm 5 \%$ striking the force platform with their right (dominant) limb. Cut angles were measured from the centre of the force plate and the corresponding line of movement was delineated using masking tape so that it was clearly evident to participants. The stance phase of the cutmovement was defined as the duration over $>20 \mathrm{~N}$ of vertical force was applied to the force platform. 
Participants began standing by on their dominant limb; they were then requested to hop forward maximally, landing on the force platform with same leg without losing balance. The arms were held across the chest to remove arm-swing contribution. The hop movement was defined as the duration from foot contact (defined as $>20 \mathrm{~N}$ of vertical force applied to the force platform) to maximum knee flexion. The hop distance for each participant was established during practice trials, and the starting position was marked using masking tape.

Hop distance for each participant was extracted as the horizontal displacement of the foot

Processing

Dynamic trials were digitized using Qualisys Track Manager in order to identify anatomical and tracking markers then exported as C3D files to Visual 3D (C-Motion, Germantown, MD, USA). Data during the appropriate phases of each movement were exported from Visual 3D into OpenSim 3.3 software (Simtk.org) using a custom pipeline that allowed the inverse kinematics to be exported in order to match the degrees of freedom associated with the experimental model in OpenSim. A previously utilized musculoskeletal model with 54 muscle-tendon units in 12 segments was adopted (Kar \& Quesada, 2012). This model differs from the traditional gait2354 approach in that a 6 degrees of freedom knee joint was included alongside ACL ligament bundles which were modelled as non-linearly elastic passive soft tissues with their proximal and distal ends inserted into the femur and tibia.

Firstly, using data from anatomical landmarks collected during the static calibration trials, the model was scaled for each participant within OpenSim (Lerner et al., 2015). In accordance with Kar \& Quesada, (2012), muscle, tendon and ligament dimensions were scaled in the 
same manner as body segments, from the static trial marker positions. Following this, we performed a residual reduction algorithm (RRA) within OpenSim to reduce the residual forces and moments in accordance with the recommendations of Lund \& Hicks, (2013). Following the RRA, the computed muscle control (CMC) procedure was then employed to estimate a set of muscle force patterns allowing the model to replicate the required kinematics.

From the above processing, the peak ACL force during the phases of each movement was extracted and normalized by dividing the net values by body mass (N/kg) (Kar \& Quesada, 2012). Further to this, the time taken from the instance of footstrike to peak ACL force (ms) was also extracted for statistical analysis. In addition, the maximum ACL strain (\%) was calculated by dividing the maximum ligament bundle length during the dynamic trials by the resting length, which was obtained during the static calibration trials (Kar \& Quesada, 2012; Taylor et al., 2013). Finally, forces of the rectus femoris, vastus intermedius, biceps femoris long head ( $\mathrm{LH})$, biceps femoris short head $(\mathrm{SH})$, gastrocnemius, sartorius, gracillis, tensor fascia lata (TFL), tibialis anterior, tibialis posterior and soleus muscle groups were quantified at the instance of peak ACL force following normalization to body mass (N/kg).

Quadriceps dominance in relation to the hamstring has been shown through electromyographical analyses to be prominent in females (Ebben et al., 2010; Landry et al., 2007; Nagano et al., 2007) and identified as a risk factor for ACL injury (Ruan et al., 2017). Musculoskeletal simulation analyses are able to generate outputs for individual knee extensor and flexor muscles (Delp et al., 2007). Therefore, they have the potential to offer further insight regarding sex differences in specific extensor and flexor muscle-tendon unit outputs, 
females. As such, flexor (biceps femoris LH, biceps femoris SH, gastrocnemius, Sartorius

at the instance of peak ACL force. Finally, as the soleus muscle has been proposed as a mechanism by which the ACL is protected during landing manoeuvres in relation to the gastrocnemius (Mokhtarzadeh et al., 2013), the soleus/ gastrocnemius ratio was also

In addition to the aforementioned muscle analyses, three dimensional knee joint angular

kinematic measures were also examined. Knee joint kinematic parameters that were extracted for statistical analysis were 1) angle at foot contact, 2) peak angle and 3) angular range of motion (ROM) from foot contact to peak angle. Furthermore, the hip flexion angle at the instance of foot contact was also extracted for further analysis. Finally, vertical and anteriorposterior GRF's were quantified at the instance of peak ACL force following normalization to body mass $(\mathrm{N} / \mathrm{kg})$.

Analyses

Descriptive statistics of means and standard deviations (SD) were obtained for each outcome measurement. Shapiro-Wilk tests were used to screen the data for normality. For the cut movement, sex differences in ACL loading and muscle force parameters were examined using univariate ANOVA's. In addition, as hop distance was statistically larger in male athletes $(1.66 \pm 0.11 \mathrm{~m})$ compared to females $(1.32 \pm 0.17 \mathrm{~m})$, sex differences in ACL and muscle forces were examined using a univariate ANCOVA with hop distance as the covariate. This was undertaken due to the increased vertical and anterior-posterior GRF's 
associated with greater landing distances (Barker et al., 2017). Statistical significance throughout was accepted at the $\mathrm{P} \leq 0.05$ level, and effect sizes were calculated using partial

$241 \operatorname{Eta}^{2}\left(\mathrm{p \eta}^{2}\right)$. All statistical actions were conducted using SPSS v24.0 (SPSS Inc, Chicago, 242 USA).

244 Results

245 Cut movement

246 The soleus/ gastrocnemius ratio at the instance of peak ACL force was significantly larger in 247 males (Table 1). In addition, knee peak valgus, internal rotation and internal rotation ROM 248 were shown to be significantly larger in females (Table 2).

@@@TABLE 1 NERE HERE@@@

254 For the hop movement, females were associated with significantly increased peak ACL 255 forces and peak ACL strains (Table 3). In addition, the soleus/ gastrocnemius ratio at the instance of peak ACL force was significantly larger in males (Table 3). Finally, knee peak valgus and internal rotation were shown to be significantly larger in females (Table 4). 


\section{Discussion}

263 The aim of the current investigation was to examine sex differences in ACL loading 264 parameters during cut and hop movements. To the authors' knowledge, this represents the 265 first investigation to quantify ACL forces and strains in male and female athletes using a 266 musculoskeletal simulation based approach. Given the debilitating nature of ACL 267 pathologies, the high incidence of re-injury and the increased susceptibility to degenerative 268 joint disease secondary to ACL injury, a study of this nature may provide important information to inform future prevention and rehabilitation programmes.

For the cut movement, the current investigation provided scant support for the hypothesis in that although very small increases in ACL loading parameters were noted in female athletes, the differences did not reach statistical significance. For the more dynamically and functionally challenging hop movement however, the findings support our hypotheses as both peak ACL force and ACL strain were shown to be statistically larger in females when adjusted for the influence of hop length through covariate analyses. This concurs with the observations of Schilaty et al., (2018), who showed using cadaveric impacts that female ligaments experience greater strain than males during a simulated landing task. Mechanically, ACL injuries occur when the ligament experiences excessive tensile forces and strains. Therefore, given the statistical differences between sexes during the hop movement and with the ACL strain being larger in female athletes, this finding may provide biomechanical insight regarding the aetiology of injury in females. 
Female athletes are believed to exhibit riskier biomechanics and increased quadriceps dominance during landing (Voskanian, 2013). The kinematic observations from the current investigation support the aforementioned notion, as females were associated with statistically greater coronal and transverse plane knee joint kinematics during both movements. Increases in knee valgus have been reported previously (Ford et al., 2003; Russell et al., 2006; Kernozek et al., 2005), and may be pertinent in relation to the increased incidence of ACL injury in females. Prospective analyses show that athletes experiencing ACL injury exhibited knee valgus angles $\geq 8^{\circ}$ than those who remained uninjured (Hewett et al., 2005). Furthermore, following ACL rupture, lateral epicondyle bone bruises are evident in $80 \%$ of cases, further implicating the valgus position of knee joint in relation to the aetiology of ACL pathologies (Viskontas et al, 2008). In addition, increased knee internal rotation in female athletes agrees with previous analyses (Kiriyama et al., 2008; Sinclair et al., 2012), and given recent observations may be clinically meaningfully regarding the increased likelihood of ACL injuries in females. Based on video analyses of ACL ruptures post injury, it was initially proposed that external rotation was the transverse plane knee mechanism responsible for ACL injuries (Ebstrup \& Bojsen-Molle, 2000). However, Koga et al., (2010) and Koga et al., (2011) have shown that the knee exhibits internal rotation until ligament failure, following which the direction of knee rotation reverses. Therefore, prophylactically attenuating knee valgus and internal rotation measures in female athletes either using movement re-training or via external supports should remain a key objective for trainers and physical therapy professionals alike.

Furthermore, in addition to riskier biomechanics females are purported to exhibit increased quadriceps dominance during landing (Voskanian, 2013). Previous electromyographical analyses have revealed a diminished hamstring/ quadriceps ratio in females (Nagano et al., 
2007). The current investigation is the first to explore potential quadriceps dominance in females using muscle forces provided by musculoskeletal simulation. However, the findings from the current study do not appear to support the aforementioned concept of quadriceps dominance in female athletes. Firstly, there were no statistical sex differences in quadriceps muscle forces and secondly none of the sex differences in any of the quadriceps muscle force ratio's reached statistical significance.

Importantly, the musculoskeletal model utilized in this investigation also quantified both soleus and gastrocnemius forces. The kinetics of these two muscles are typically ignored in analyses concerning the loads experienced by the ACL owing of the supposition that they have limited influence due to the muscles lines of action being close to the long axis of the tibia (Mokhtarzadeh et al., 2013). However, previous modelling analyses by Mokhtarzadeh et al., (2013) and Adouni et al., (2016) have shown that the soleus protects the ACL during landing manoeuvres by exerting a posterior force on the tibia and that the gastrocnemius acts as an ACL antagonist. The current investigation showed that the muscle force ratio between the soleus and gastrocnemius muscles was statistically larger in male athletes, indicating a more favourable ratio in terms of protection from ACL injuries during high intensity athletic movements.

A potential limitation to the current investigation is the mechanism by which the simulation analyses were conducted. Although a powerful tool that has been utilized in previous analyses to simulate ACL mechanics (Kar \& Quesada, 2013), the CMC processes is insensitive to variations in muscle activation and limited in its ability to quantify muscle coordination during dynamic tasks (Zajac et al., 2002). As both of these parameters have 
been shown previously to exhibit both sex and movement differences (Nagano et al., 2007), this may represent a methodological drawback to the current study. In addition, the lack of sex specificity in regards to the anatomy and scaling of the ACL may serve as a limitation to this investigation. As the ACL contributes significantly to knee joint load bearing and stability, incorporation of a sex specific scaling mechanism may improve the efficacy of musculoskeletal simulation analyses concerning the knee joint. That ACL strain was quantified by standardizing ligament elongation to a resting length obtained during the static calibration trial, may also represent a drawback to this instigation. Although this procedure was selected in accordance with Kar \& Quesada, (2012) and Taylor et al., (2013), due to the complications associated with determining an accurate in vivo resting length (Fleming and Beynnon, 2004) and there remains some uncertainty regarding the accuracy of true strain values. Finally, as three-dimensional knee kinematics were quantified using skin mounted markers this may serve as a limitation. Particularly in light of the findings provided by Benoit et al., (2006) indicating that kinematic waveforms produced using this technique may not be representative of the motion of the underlying bones.

In conclusion, the current investigation adds to the current literature by exploring sex differences in ACL loading, GRF's, three-dimensional knee kinematics and muscle forces using a musculoskeletal simulation based approach. Importantly, the findings from this study showed that during the hop movement, females were associated with significantly greater peak ACL forces and strains. In addition, for both movements the soleus/ gastrocnemius ratio at the instance of peak ACL force was significantly larger in male athletes. Therefore, the current investigation provides new information regarding sex differences during athletic movements that provide further insight regarding the increased incidence of ACL injuries in females. 


\section{References}

360

361

362

363

1. Adouni M, Shirazi-Adl A, Marouane H (2016). Role of gastrocnemius activation in knee joint biomechanics: gastrocnemius acts as an ACL antagonist. Comput Methods Biomech Biomed Engin 19: 376-385.

2. Ajuied A, Wong F, Smith C, Norris M, Earnshaw P, Back D, Davies A (2014). Anterior cruciate ligament injury and radiologic progression of knee osteoarthritis: a systematic review and meta-analysis. Am J Sports Med 42: 2242-2252.

3. Arendt EA, Agel J, Dick R (1999). Anterior cruciate ligament injury patterns among collegiate men and women. J Athl Train 34: 86-92.

4. Baratta R, Solomonow M, Zhou B.H, Letson D, Chuinard R, D'Ambrosia R. (1988). Muscle coactivation: the role of the antagonist musculature in maintaining knee stability. Am J Sports Med 16: 113-122.

5. Barker LA, Harry JR, Mercer JA. (2018). Relationships between countermovement jump ground reaction forces and jump height, reactive strength index, and jump time. J Strength Cond Res 32: 248-254.

6. Benoit DL, Ramsey DK, Lamontagne M, Xu L, Wretenberg P, Renström P. (2005). 22.4 Effect of skin movement artifact on knee kinematics during gait and cutting motions measured in-vivo. Gait Posture 24: 152-164.

7. Boden BP, Torg JS, Knowles SB, Hewett TE. (2009). Video analysis of anterior cruciate ligament injury: abnormalities in hip and ankle kinematics. Am J Sports Med 37: $252-259$.

8. Boden BP, Sheehan FT, Torg JS, Hewett TE (2010). Non-contact ACL injuries: mechanisms and risk factors. J Am Acad Orthop Surg 18: 520-527. 
9. Caraffa A, Cerulli G, Projetti M, Aisa G, Rizzo A (1996). Prevention of anterior cruciate ligament injuries in soccer. Knee Surg Sports Traumatol Arthrosc 4: 19-21.

10. Chappell JD, Yu B, Kirkendall DT, Garrett WE (2002). A comparison of knee kinetics between male and female recreational athletes in stop-jump tasks. Am $\mathbf{J}$ Sports Med 30: 261-267.

11. Dai B, Mao D, Garrett WE, Yu B (2014). Anterior cruciate ligament injuries in soccer: Loading mechanisms, risk factors, and prevention programs. J Sport Health Sci 3: 299-306.

12. Decker MJ, Torry MR, Wyland DJ, Sterett WI, Steadman JR. (2003). Gender differences in lower extremity kinematics, kinetics and energy absorption during landing. Clin Biomech 18: 662-669.

13. Dargel J, Gotter M, Mader K, Pennig D, Koebke J, Schmidt-Wiethoff R. (2007). Biomechanics of the anterior cruciate ligament and implications for surgical reconstruction. Strategies Trauma Limb Reconstr 2: 1-12.

14. Delp SL, Anderson FC, Arnold AS, Loan P, Habib A, John CT, Thelen DG (2007). OpenSim: open-source software to create and analyze dynamic simulations of movement. IEEE Trans Biomed Eng 54: 1940-1950.

15. Di Stasi S, Myer GD, Hewett TE (2013). Neuromuscular training to target deficits associated with second anterior cruciate ligament injury. J Orthop Sports Phys Ther 43: 777-792.

16. Draganich LF, Vahey JW. (1990). An in vitro study of anterior cruciate ligament strain induced by quadriceps and hamstring forces. J Orthop Res 8: 57-63.

17. Dürselen L, Claes L, Kiefer H. (1995). The influence of muscle forces and external loads on cruciate ligament strain. Am J Sports Med 23: 129-136. 
18. Ebben WP, Fauth ML, Petushek EJ, Garceau LR, Hsu BE, Lutsch BN, Feldmann CR (2010). Gender-based analysis of hamstring and quadriceps muscle activation during jump landings and cutting. J Strength Cond Res 24: 408-415.

19. Ellison AE, Berg EE (1985). Embryology, anatomy, and function of the anterior cruciate ligament. Orthop Clin North Am 16: 3-14.

20. Evans S, Shaginaw J, Bartolozzi A (2014). ACL reconstruction it's all about timing. Int J Sports Phys Ther 9: 268-273.

21. Finch C, Owen N, Price R (2001). Current injury or disability as a barrier to being more physically active. Med Sci Sports Exerc 33: 778-782.

22. Fleming BC, Beynnon BD (2004). In vivo measurement of ligament/tendon strains and forces: a review. Ann Biomed Eng 32: 318-328.

23. Ford KR. Myer GD, Hewett TE (2003). Valgus knee motion during landing in high school female and male basketball players. Med Sci Sports Exerc 35: 1745-1750.

24. Gottlob CA, Baker CL, Pellissier JM, Colvin L (1999). Cost effectiveness of anterior cruciate ligament reconstruction in young adults. Clin Orthop Relat Res 367: 272-282.

25. Hewett TE, Stroupe AL, Nance TA, Noyes FR. (1996). Plyometric training in female athletes: decreased impact forces and increased hamstring torques. Am J Sports Med 24: $765-773$.

26. Hewett TE, Lindenfeld TN, Riccobene JV, Noyes FR (1999). The effect of neuromuscular training on the incidence of knee injury in female athletes. A prospective study. Am J Sports Med 27: 699-706.

27. Hewett TE, Myer GD, Ford KR, Heidt Jr RS, Colosimo AJ, McLean SG, Van den Bogert AJ, Paterno MV, Succop P. (2005). Biomechanical measures of neuromuscular control and valgus loading of the knee predict anterior cruciate 
ligament injury risk in female athletes: a prospective study. Am J Sports Med 33: $492-501$.

28. Huston LJ, Wojtys EM (1996). Neuromuscular performance characteristics in elite female athletes. Am J Sports Med 24: 427-436.

29. John R, Dhillon MS, Syam K, Prabhakar S, Behera P, Singh H (2016). Epidemiological profile of sports-related knee injuries in northern India: An observational study at a tertiary care centre. J Clin Orthop Trauma 7: 207-211.

30. Kar J, Quesada PM (2013). A musculoskeletal modeling approach for estimating anterior cruciate ligament strains and knee anterior-posterior shear forces in stopjumps performed by young recreational female athletes. Ann Biomed Eng 41: 338348.

31. Kaeding CC, Pedroza AD, Reinke EK, Huston LJ, Spindler KP. (2015). Risk factors and predictors of subsequent ACL injury in either knee after ACL reconstruction: prospective analysis of 2488 primary ACL reconstructions from the MOON cohort. Am J Sports Med 43: 1583-1590.

32. Kernozek TW, Torry MR, Van Hoof H, Cowley H, Tanner S. (2005). Gender differences in frontal and sagittal plane biomechanics during drop landings. Med Sci Sports Exerc 37: 1003-1012.

33. Kernozek T, Torry M, Shelburne K, Durall CJ, Willson J. (2013). From the gait laboratory to the rehabilitation clinic: translation of motion analysis and modeling data to interventions that impact anterior cruciate ligament loads in gait and drop landing. Crit Rev Biomed Eng 41: 243-258.

34. Kiriyama S, Sato H, Takahira N. (2009). Gender differences in rotation of the shank during single-legged drop landing and its relation to rotational muscle strength of the knee. Am J Sports Med 37: 168-174. 
35. Koga H, Nakamae A, Shima Y, Iwasa J, Myklebust G, Engebretsen L, Krosshaug T. (2010). Mechanisms for noncontact anterior cruciate ligament injuries: knee joint kinematics in 10 injury situations from female team handball and basketball. Am J Sports Med 38: 2218-2225.

36. Koga H, Bahr R, Myklebust G, Engebretsen L, Grund T, Krosshaug T. (2011). Estimating anterior tibial translation from model-based image-matching of a noncontact anterior cruciate ligament injury in professional football: a case report. Clin J Sport Med 21: 271-274.

37. Krosshaug T, Nakamae A, Boden BP, Engebretsen L, Smith G, Slauterbeck JR, Hewett TE, Bahr R. (2007). Mechanisms of anterior cruciate ligament injury in basketball: video analysis of 39 cases. Am J Sports Med 35: 359-367.

38. LaBella CR, Huxford MR, Grissom J, Kim KY, Peng J, Christoffel KK (2011). Effect of neuromuscular warm-up on injuries in female soccer and basketball athletes in urban public high schools: cluster randomized controlled trial. Arch Pediatr Adolesc Med 165: 1033-1040.

39. Landry SC, McKean KA, Hubley-Kozey CL, Stanish WD, Deluzio KJ (2007). Neuromuscular and lower limb biomechanical differences exist between male and female elite adolescent soccer players during an unanticipated side-cut maneuver. The Am J Sports Med 35: 1888-1900.

40. Lephart SM, Ferris CM, Riemann BL, Myers JB, Fu FH (2002). Gender differences in strength and lower extremity kinematics during landing. Clin Orthop Relat Res 401: 162-169.

41. Lerner, Z. F., Board, W. J., \& Browning, R. C. (2016). Pediatric obesity and walking duration increase medial tibiofemoral compartment contact forces. J Orthop Res 34: 97-105. 
42. Li G, Rudy TW, Sakane M, Kanamori A, Ma CB, Woo SY (1999). The importance of quadriceps and hamstring muscle loading on knee kinematics and in-situ forces in the ACL. J Biomech 32: 395-400.

43. Lin CF, Liu H, Gros MT, Weinhold P, Garrett WE, Yu B (2012). Biomechanical risk factors of non-contact ACL injuries: A stochastic biomechanical modeling study. J Sport Health Sci 1: 36-42.

44. Lund K, Hicks J (2013). Getting Started with RRA. Retrieved 10.10.2018, from https://simtkconfluence.stanford.edu:8443/display/OpenSim/Getting+Started+with+RRA

45. Malinzak RA, Colby SM, Kirkendall DT, Yu B, Garrett WE (2001). A comparison of knee joint motion patterns between men and women in selected athletic tasks. Clinical Biomech 16: 438-445.

46. Mandelbaum BR, Silvers HJ, Watanabe DS (2005). Effectiveness of a neuromuscular and proprioceptive training program in preventing anterior cruciate ligament injuries in female athletes: 2-year follow-up. Am J Sports Med 33: 1003-1010.

47. Markolf KL, Burchfield DM, Shapiro MM, Shepard MF, Finerman GA, Slauterbeck JL. (1995). Combined knee loading states that generate high anterior cruciate ligament forces. J Orthop Res 13: 930-935.

48. Markolf KL, O'Neil G, Jackson SR, McAllister DR. (2004). Effects of applied quadriceps and hamstrings muscle loads on forces in the anterior and posterior cruciate ligaments. Am J Sports Med 32: 1144-1149.

49. Mather RC, Koenig L, Kocher MS, Dall TM, Gallo P, Scott DJ (2013). Societal and economic impact of anterior cruciate ligament tears. J Bone Joint Surg 95: 1751-1759. 
50. Mokhtarzadeh H, Yeow CH, Goh JCH, Oetomo D, Malekipour F, Lee PVS (2013). Contributions of the soleus and gastrocnemius muscles to the anterior cruciate ligament loading during single-leg landing. J Biomechanics 46: 1913-1920.

51. Myklebust G, Engebretsen L, Braekken IH (2003). Prevention of anterior cruciate ligament injuries in female team handball players: a prospective intervention study over 3 seasons. Clin J Sport Med 13: 71-78.

52. Nagano Y, Ida H, Akai M, Fukubayashi T. (2007). Gender differences in knee kinematics and muscle activity during single limb drop landings. Knee 14: 218-223.

53. Øiestad BE, Engebretsen L, Storheim K, Risberg MA (2009). Knee osteoarthritis after anterior cruciate ligament injury a systematic review. Am J Sports Med 37: 14341443.

54. Olsen OE, Myklebust G, Engebretsen L, Bahr R (2004). Injury mechanisms for anterior cruciate ligament injuries in team handball: a systematic video analysis. Am J Sports Med 32: 1002-1012.

55. Quatman CE, Hewett TE. (2009). The ACL injury controversy: is "valgus collapse" a sex-specific mechanism?. Br J Sport Med 43: 328-335.

56. Ruan M, Zhang Q, Wu X (2017). Acute effects of static stretching of hamstring on performance and anterior cruciate ligament injury risk during stop-jump and cutting tasks in female athletes. J Strength Cond Res 31: 1241-1250.

57. Russell KA, Palmieri RM, Zinder SM, Ingersoll CD. (2006). Sex differences in valgus knee angle during a single-leg drop jump. J Athl Train 41: 166-171.

58. Schilaty ND, Bates NA, Nagelli CV, Krych AJ, Hewett TE (2018). Sex-Based Differences of Medial Collateral Ligament and Anterior Cruciate Ligament Strains With Cadaveric Impact Simulations. Orthop J Sports Med 6: 2325967118765215. 
59. Shelbourne K, Nitz P. (1992). Accelerated rehabilitation after anterior cruciate ligament reconstruction. J Orthop Sports Phys Ther 15:256-264.

60. Shimokochi Y, Shultz SJ. (2008). Mechanisms of noncontact anterior cruciate ligament injury. J Athl Train 43: 396-408.

61. Sinclair J, Greenhalgh A, Edmundson CJ, Brooks D, Hobbs SJ. (2012). Gender differences in the kinetics and kinematics of distance running: implications for

\section{footwear design. Int J Sport Sci Eng 6: 118-128.}

62. Smith HC, Vacek P, Johnson RJ, Slauterbeck JR, Hashemi J, Shultz S, Beynnon BD (2012). Risk factors for anterior cruciate ligament injury: a review of the literaturepart 1: neuromuscular and anatomic risk Sport Health 4: 69-78.

63. Solomonow M, Baratta R, Zhou BH, Shoji H, Bose W, Beck C, D'ambrosia R. (1987). The synergistic action of the anterior cruciate ligament and thigh muscles in maintaining joint stability. Am J Sports Med 15: 207-213.

64. Taylor K, Cutcliffe HC, Queen RM, Utturkar GM, Spritzer CE, Garrett WE, DeFrate LE. In vivo measurement of ACL length and relative strain during walking. J Biomech 2013 46: 478-483.

65. Viskontas DG, Giuffre BM, Duggal N, Graham D, Parker D, Coolican M. (2008). Bone bruises associated with ACL rupture: correlation with injury mechanism. Am J Sports Med. 36: 927-933.

66. Voskanian N (2013). ACL Injury prevention in female athletes: review of the literature and practical considerations in implementing an ACL prevention program. Curr Rev Musculoskelet Med 6: 158-163.

67. Warburton DE, Nicol CW, Bredin SS (2006). Health benefits of physical activity: the evidence. Can Med Assoc J 174: 801-809. 
68. Wascher DC, Markolf KL, Shapiro MS, Finerman GA. (1993). Direct in vitro measurement of forces in the cruciate ligaments. Part I: The effect of multiplane loading in the intact knee. J Bone Joint Surg Am 75: 377-386.

69. Yu B, Garrett WE (2007). Mechanisms of non-contact ACL injuries. Br J Sport Med 41: 47-51.

556

70. Zajac FE, Neptune RR, Kautz SA. (2002). Biomechanics and muscle coordination of 557 human walking: Part I: Introduction to concepts, power transfer, dynamics and simulations. Gait Posture 16: 215-232. 